\title{
Prevalence of lower extremity Peripheral artery disease among adult diabetes patients in Southwestern Uganda
}

\author{
Samson Okello ${ }^{1 *}$, Alexander Millard ${ }^{2}$, Rogers Owori ${ }^{1}$, Stephen Bambeiha Asiimwe ${ }^{3}$, Mark Jacob Siedner ${ }^{4}$, \\ Joselyn Rwebembera', Laurence Anthony Wilson', Christopher Charles Moore ${ }^{2}$ and Brian Herb Annex ${ }^{2,5}$
}

\begin{abstract}
Background: Peripheral artery disease (PAD) is a major complication of atherosclerosis. PAD can be diagnosed with low-cost diagnostic techniques and is associated with significant morbidity and mortality. While the major epidemiologic risk factors for PAD have been established in the western world, data from resource-poor countries are limited. We performed a cross-sectional study to determine the prevalence and correlates of PAD among patients with diabetes at Mbarara Referral Hospital in southwestern Uganda.
\end{abstract}

Methods: We consecutively enrolled diabetes patients aged 50 years or greater presenting to the outpatient clinic. We collected blood for fasting lipid profile, HIV serology, and glycosylated hemoglobin, measured blood pressure and ankle brachial index, and administered the Edinburgh Claudication Questionnaire (ECQ). We also surveyed patients for other PAD risk factors. We used logistic regression to determine correlates of PAD.

Results: We enrolled 229 diabetes patients. The median age of 60 years (IQR 55-66), and 146 (63.7\%) were female. Fifty five patients (24\%) had PAD (ABI of $\leq 0.9)$. Of these, $48 / 55$ (87.27\%) had mild PAD (ABI 0.71-0.9) while 7/55 (12.73\%) had moderate to severe PAD $(A B \mid<0.7)$. Amongst those with PAD, $24 / 55(43.64 \%)$ reported claudication by the ECQ. Correlates of PAD included female sex (AOR 2.25, 95\% Cl $1.06-4.77, p=0.034$ ), current high blood pressure (AOR 2.59, 95\% Cl 1.25-5.33, $\mathrm{p}=0.01$ ), and being on a sulfonylurea-glibenclamide (AOR 3.47, 95\% Cl 1.55 - 7.76, $\mathrm{p}=0.002)$.

Conclusion: PAD was common in diabetic patients in southwestern Uganda. Given its low cost and ease of measurement, $\mathrm{ABI}$ deserves further assessment as a screening tool for both PAD and long term cardiovascular risk amongst diabetics in this region.

\section{Background}

Cardiovascular disease is projected to become the leading cause of death in sub-Saharan Africa within the next two decades [1]. This epidemiologic shift will have a significant impact on health and relative burden of disease in the region [2]. Epidemiologic data on non-communicable diseases in this region are lacking and this is in part due to the non-availability and high cost of diagnostic tools.

Peripheral arterial disease (PAD) is among those noncommunicable diseases that can be diagnosed without skilled technologists and at low cost by measurement of

\footnotetext{
* Correspondence: okello.samson@must.ac.ug

${ }^{1}$ Department of Medicine, Mbarara University of Science and Technology, P.O Box 1410, Mbarara, Uganda

Full list of author information is available at the end of the article
}

the ankle brachial index (ABI). The $\mathrm{ABI}$, therefore, presents an attractive screening tool for PAD in resourcepoor settings. Studies in resource-rich settings have shown that ABI is both sensitive and specific as a measure of lower extremity large vessel atherosclerosis [3-5]. In western countries, PAD patients are at high risk of myocardial infarction, stroke, amputations, and cardiovascular disease related death. Despite this, many patients with PAD are asymptomatic [6-8]. PAD, therefore, is an attractive target for screening because its early detection may not only help to delay its progression, but may also enable improved management of overall cardiovascular risk [9-14].

While in resource-rich settings, diabetes, smoking, and old age have been identified as the most important risk 
factors for PAD [15-17], in Sub-Saharan Africa, PAD is rarely diagnosed, in both diabetic and non-diabetic patients. Consequently, neither is the prevalence of PAD, nor its risk factors well understood in this region. A better understanding of PAD in a population with diabetes may help guide further research and identify potential intervention targets. For example, detection of PAD in such a high risk population may allow for the institution of relatively simple and low cost medical therapies with the potential to improve overall cardiovascular risk such as aspirin, 3-hydroxy-3-methyl-glutaryl-CoA reductase inhibitors (statins like artovastatin), and angiotensin converting enzyme (ACE) inhibitors [18]. We, therefore, performed a cross-sectional study to determine the prevalence and correlates of PAD among patients with diabetes at Mbarara Referral Hospital in Southwestern Uganda. We hypothesized that diabetic patients in sub-Saharan Africa would have a prevalence of PAD of $28 \%$ (with a $10 \%$ precision) based on what has been found in resource-rich settings (95\% CI 19-29\%) [19].

\section{Methods}

\section{Study design and population}

We consecutively enrolled all fasting diabetes patients of black race, aged $\geq 50$ years [20], who presented to the diabetes outpatient clinic at Mbarara Regional Referral Hospital in Southwestern Uganda, between January and June 2012. To be included, patients had to have fasted on the morning of their clinic appointment. Routinely at this clinic, all patients are advised to fast on the morning of their clinic appointment to allow for the measurement of their fasting blood glucose. We excluded patients with lower limb amputations and those with suspicion of deep vein thrombosis (i.e., unilateral leg swelling, constant calfmuscle pain, and pain on foot flexion) for whom ABI testing would have been inappropriate. All patients gave written informed consent to participate and ethics approval was obtained from Mbarara University of Science and Technology and University of Virginia Institutional Review Boards. The study was registered with the Uganda National Council of Science and Technology.

\section{Data collection \\ Clinical and demographic variables}

We surveyed the patients to collect data on smoking history, hypertension, hyperlipidemia, stroke/transient ischemic attack, coronary artery disease, or chronic kidney disease. We also obtained data on the duration of diabetes and current medications. We categorized self-reported smoking as never, former, or current. A physician verbally administered the Edinburgh Claudication Questionnaire (ECQ). The ECQ has been shown in English speaking populations to be $91.3 \%$ sensitive and $99.3 \%$ specific for identifying claudication symptoms [21]. To adapt it to this population, the ECQ was pre-tested and translated into the local language (Runyankole). In addition, we ensured that it was administered by a physician fluent in the local language. Given that responses were quantitative, back translation was not done, and the data was entered directly into a database. A composite variable derived from the responses classified claudication as: none, atypical, or definite claudication. From the ECQ, definite claudication was defined as presence of calf pain, regardless of whether there was pain at other sites. Atypical claudication was defined as having pain in the thigh or buttock in the absence of calf pain. Finally, no claudication was defined as having pain in the hamstrings, feet, shins, joints, or any calf, thigh or buttock pain that appears to radiate, or no pain at all in any part of the leg [21].

\section{Measurement of $\mathrm{ABI}$}

For all patients, we measured the brachial blood pressure (BP) after a 5-minute rest in the supine position, using an aneroid sphygmomanometer (Welch Allyn ${ }^{\circ}$ Tycos DS58 Hand Aneroids; Skaneateles Falls, New York, USA), recalibrated monthly according to the manufacturers' manual. Two BP measurements were taken for each arm with a third reading performed only if the difference between the two was greater than $10 \mathrm{mmHg}$ for systolic BP, or greater than $5 \mathrm{mmHg}$ for diastolic BP. The mean of the closest two readings was then calculated and taken as the patient's BP.

We measured ankle pressures using an aneroid sphygmomanometer while using a standardized Doppler ultrasonic device (8 MHz; Edan ${ }^{\text {Tm }}$ Sonotrax ${ }^{\ominus}$ MS3-14347A; Shekou, China) to accentuate the sounds over the posterior tibial and dorsalis pedis arteries. The ankle-brachial index for each leg was calculated by dividing the higher of two systolic BP readings at the ankle (i.e., one from the dorsalis pedis and the other from the posterior tibial artery) by the higher of the two brachial systolic BP readings from the ipsilateral arm (i.e., from the brachial artery). For all patients, measurements on both legs were obtained, and the lower value was considered as the patient's ABI [20,22,23].

\section{Laboratory-based measurements}

We measured fasting blood glucose level and glycosylated hemoglobin (HbA1c) levels using a hand-held glucometer (Abbott Optium Xceed ${ }^{\circ}$ Diabetes Monitoring System; Abbott laboratories ${ }^{\mathrm{Tw}}$, Illinois, USA) and a standard HbA1c rapid test kit (A1CNow $+{ }^{\circ}$; Bayer ${ }^{\text {Tn }}$ HealthCare, Sunnyvale, CA, USA) respectively. We also tested patients for HIV serology using a standard algorithm and standard rapid testing kits, with a sensitive initial screen (Alere $^{\mathrm{Tn}}$ HIV-1/2 Determine dipstick) followed by a more specific confirmatory test(STAT-PAK ${ }^{\circ}$ HIV-1/2), with only the inconclusive results being subjected to a third rapid test as a tie breaker (Uni-Gold ${ }^{\mathrm{TM}}$ Recombigen $^{\circ}$ HIV). In addition, we 
obtained serum total cholesterol (TC), triglyceride (TG), high-density lipoprotein cholesterol (HDL-C), and lowdensity lipoprotein cholesterol (LDL-C) levels, using an automated clinical chemistry analyzer (Humastar ${ }^{\circ}$ 180; Human Diagnostics Worldwide, Wiesbaden, Germany). The tests were performed at the Mbarara University Clinical Research Laboratory which participates in external quality assurance programs by the National Health Laboratory Service (Johannesburg, South Africa).

\section{Study definitions}

We defined diabetes as a fasting glucose level $\geq 7.0 \mathrm{mmol} / \mathrm{L}$ $(127 \mathrm{mg} / \mathrm{dL})$, or taking medication for diabetes, or having been diagnosed with diabetes by a physician. We defined poor glycemic control as HbA1c $>7.0 \%$ (> $53 \mathrm{mmol} / \mathrm{mol})$ [24]. Hypertension was defined as a systolic blood pressure $\geq 140 \mathrm{mmHg}$ or diastolic blood pressure $\geq 90 \mathrm{mmHg}$ or having been on hypertensive medications. Obesity was defined as a BMI $\geq 30 \mathrm{~kg} / \mathrm{m}^{2}$, or a waist-to-hip ratio $\geq 0.81$ or $\geq 0.96$ for females and males respectively [25]. We defined hypercholesterolemia, high LDLcholesterol, low HDL-cholesterol, hypertriglyceridemia, respectively, as serum cholesterol levels greater than $190 \mathrm{mg} / \mathrm{L}(4.9 \mathrm{mmol} / \mathrm{L})$, LDL-cholesterol greater than $100 \mathrm{mg} / \mathrm{dL}(2.50 \mathrm{mmol} / \mathrm{L})$, HDL-cholesterol levels less than $40 \mathrm{mg} / \mathrm{L}(1.03 \mathrm{mmol} / \mathrm{L})$, and serum triglyceride levels greater than $200 \mathrm{mg} / \mathrm{L}(2.26 \mathrm{mmol} / \mathrm{L})$ respectively [26]. We defined mild PAD as an $\mathrm{ABI} \geq 0.71$ but $\leq 0.90$, moderate $\mathrm{PAD}$ as an $\mathrm{ABI} \geq 0.40$ but $\leq 0.70$, and severe PAD as an $\mathrm{ABI}<0.40$ [20]. We considered a patient with PAD as being on PAD-appropriate medical therapy if they reported taking either aspirin or clopidigrel. However, for those with hypertension required an additional drug in form of a statin, or an ACEI to be considered as being on PAD appropriate therapy.

\section{Statistical methods}

We summarized demographic and clinical characteristics, reporting proportions for categorical and binary variables, and median and interquartile range for continuous variables. We further divided the cohort into those with and without PAD and fit logistic regression models to determine the correlates PAD. In the multivariable models, we adjusted for sex, current high blood pressure, and taking glibenclamide). Statistical significance was set at $p \leq 0.05$. We performed all statistical analyses using Stata 12 (StataCorp, College Station, Texas, USA).

\section{Results}

Of 256 patients who were screened, 27 did not meet inclusion criteria and were excluded. Thirteen were aged $\leq$ 49 years, eight had no diabetes, one had an above-knee amputation, five declined participation, two withdrew consent, and one did not complete study procedures.
Summary demographic and clinical characteristics for the remaining 229 patients are shown in Table 1. The cohort had a median age of 60 years, had been known to be diabetic for a median of 1.0 year (IQR 0.3-2.3), and had a median HbA1c of 8.1\% (6.7-10.1). Twenty-nine percent were taking insulin, and $41 \%$ were former or current smokers.

The prevalence of PAD (ABI of $\leq 0.9)$ was $24 \%(55 / 229)$. Among the patients with PAD, 48/55 (87\%) had mild PAD (ABI 0.71-0.90) while 7/55 (13\%) had moderate to severe PAD (ABI < 0.70). Based on the ECQ, 31/55 (56\%) of those with PAD were asymptomatic, whereas only $11 / 55(20 \%)$ showed definite claudication, and 13/55 (24\%) had atypical

\section{Table 1 Characteristics of the study population}

\begin{tabular}{|c|c|}
\hline Characteristic & $N=229$ \\
\hline Age (years), median (IQR) & $60(55-66)$ \\
\hline Female sex, n (\%) & $146(63.7)$ \\
\hline Current smoker, n (\%) & $12(5.2)$ \\
\hline Former smoker, n (\%) & $82(35.8)$ \\
\hline Never smoked & $135(59)$ \\
\hline Duration of diabetes (years), median (IQR) & $1.0(0.3-2.3)$ \\
\hline Family history of diabetes, n (\%) & $78(34.1)$ \\
\hline No Claudication, n (\%) & $126(55.0)$ \\
\hline Atypical Claudication, n (\%) & $54(23.6)$ \\
\hline Definite Claudication, n (\%) & $49(21.4)$ \\
\hline Self-reported hypertension, n (\%) & $113(49.3)$ \\
\hline HIV infection, n (\%) & $18(7.9)$ \\
\hline \multicolumn{2}{|l|}{ Diabetes treatment ${ }^{\pi}, \mathrm{n}(\%)$} \\
\hline Metformin only & $112(51.6)$ \\
\hline Glibenclamide only & $2(0.9)$ \\
\hline Glibenclamide and Metformin & $34(15.7)$ \\
\hline Insulin only & $52(24)$ \\
\hline Insulin and Metformin & $15(6.9)$ \\
\hline Aspirin, $n(\%)$ & $17(7.4)$ \\
\hline BMI $\left(\mathrm{kg} / \mathrm{m}^{2}\right)$, median $(\mathrm{IQR})$ & $26.3(22.6-29.4)$ \\
\hline Waist-to-hip ratio, median (IQR) & $1(1-1)$ \\
\hline Systolic blood pressure $(\mathrm{mmHg})$, median (IQR) & $140(124-160)$ \\
\hline Diastolic blood pressure $(\mathrm{mmHg})$, median (IQR) & $80(70-90)$ \\
\hline Fasting blood sugar (mmol/L), median (IQR) & $8.6(6.6-13.7)$ \\
\hline HbA1c (\%), median (IQR) & $8.1(6.7-10.1)$ \\
\hline $\mathrm{HDL}^{ \pm}$-Cholesterol (mg/dL), median (IQR) & $48(39-58)$ \\
\hline $\mathrm{LDL}^{*}$-Cholesterol (mg/dL), median (IQR) & $81(63-96)$ \\
\hline Triglycerides (mg/dL), median (IQR) & $116(83-179)$ \\
\hline Total cholesterol (mg/dL), median (IQR) & $268(212-307)$ \\
\hline
\end{tabular}

IQR: Inter quartile range; HIV: Human immunodeficiency virus; BMI: body mass index; $\mathrm{HDL}^{ \pm}$: High-density Lipoprotein- cholesterol; LDL ${ }^{*}$ : Low-density lipoprotein-cholesterol; HbA1c: glycated hemoglobin.

Diabetes treatment ${ }^{\pi}$ : A total of 217 patients were on diabetes medication. 
claudication symptoms. Additionally, among those with PAD, 6/55 (11\%) were taking aspirin, and only 1 patient was taking a statin. Thirty three of 113 (29.2\%) patients who had hypertension with concurrent PAD were on an ACE inhibitor or ARB.

In the unadjusted analysis (Table 2), female sex, selfreported hypertension, current high blood pressure, and duration of diabetes were associated with PAD. In the multivariable adjusted analysis, (Table 3), female sex (AOR 2.25, 95\% CI 1.06-4.77, $\mathrm{p}=0.034$ ), current high blood pressure (AOR 2.59, 95\% CI 1.25-5.33, $\mathrm{p}=0.01$ ), and being on sulfonylurea-glibenclamide (AOR 3.47, $95 \%$ CI $1.55-7.76, \mathrm{p}=0.002$ ) were independently associated with PAD.

\section{Discussion}

To the best of our knowledge, this is the first report of the prevalence of PAD in patients with diabetes in SubSahara Africa. The prevalence of PAD of $24 \%$, as found in our study based on ABI, was substantially higher than previous estimates $(0.2-3.4 \%)$ which were based on clinical parameters such as weak or absent peripheral pulses, or development of dry gangrene [27,28]. However, our

Table 2 Unadjusted analysis of predictors of Peripheral Artery Disease

\begin{tabular}{|c|c|c|}
\hline Characteristic & OR $(95 \% \mathrm{Cl})$ & p-value \\
\hline Female sex & $2.47(1.22-5.01)$ & 0.0001 \\
\hline Smoking history & $1.04(0.56-1.93)$ & 0.894 \\
\hline Duration of diabetes $>5$ years & $3.38(0.94-12.15)$ & 0.062 \\
\hline Family history of diabetes & $1.37(0.73-2.56)$ & 0.326 \\
\hline Presence of claudication symptoms & $0.93(0.51-1.71)$ & 0.819 \\
\hline Self-reported hypertension ${ }^{*}$ & $1.96(0.95-3.26)$ & 0.072 \\
\hline Current elevated blood pressure $^{\beta}$ & $2.73(1.42-5.25)$ & 0.003 \\
\hline HIV infection & $0.61(0.17-2.19)$ & 0.451 \\
\hline Metformin use & $0.74(0.39-1.42)$ & 0.367 \\
\hline Glibenclamide use & $3.16(1.50-6.66)$ & 0.002 \\
\hline Insulin use & $1.24(0.65-2.38)$ & 0.517 \\
\hline Obesity, BMI $\geq 30 \mathrm{Kg} / \mathrm{m}^{2}$ & $1.23(0.59-2.53)$ & 0.576 \\
\hline Waist-to-hip ratio $\geq 0.81$ (F) or $\geq 0.96$ (M) & $0.83(0.21-3.26)$ & 0.796 \\
\hline Cholesterol $\geq 190 \mathrm{mg} / \mathrm{dL}$ & $0.9(0.41-1.98)$ & 0.794 \\
\hline $\mathrm{HDL}^{\epsilon} \leq 40 \mathrm{mg} / \mathrm{dL}$ & $1.21(0.61-2.41)$ & 0.581 \\
\hline $\mathrm{LDL}^{\mathrm{a}} \geq 100 \mathrm{mg} / \mathrm{dL}$ & $1.39(0.69-2.78)$ & 0.355 \\
\hline $\mathrm{TG}^{\infty} \geq 200 \mathrm{mg} / \mathrm{dL}$ & $0.75(0.34-1.67)$ & 0.483 \\
\hline $\mathrm{FBS}^{\mu}<3.9$ or $>7.2 \mathrm{mmol} / \mathrm{L}$ & $0.87(0.46-1.65)$ & 0.679 \\
\hline $\mathrm{HbA} 1 \mathrm{c}^{£}>7.0 \%(53 \mathrm{mmol} / \mathrm{mol})$ & $0.75(0.39-1.41)$ & 0.368 \\
\hline
\end{tabular}

Self-reported hypertension ${ }^{*}$ : prior diagnosis of hypertension and taking antihypertensive drugs; Current elevated blood pressure ${ }^{\beta}$ : clinic systolic blood pressure $\geq 140 \mathrm{mmHg}$ and/or diastolic blood pressure $\geq 90 \mathrm{mmHg}$; OR: Odds ratio; BMI: body mass index; $\mathrm{HDL}^{\epsilon}$ : High-density Lipoprotein- cholesterol; $\mathrm{LDL}^{\mathrm{a}}$ : Low-density lipoprotein-cholesterol; $\mathrm{TG}^{\circ}$ : Triglycerides; $\mathrm{FBS}^{\mu}$ : fasting blood sugar; $\mathrm{HbA}^{\mathrm{f}} \mathrm{c}^{\mathrm{f}}$ : glycated hemoglobin.
Table 3 Multivariable adjusted predictors of Peripheral Artery Disease

\begin{tabular}{lccc}
\hline Characteristic & AOR & 95\% Cl & p-value \\
\hline Glibenclamide use & 3.47 & $1.55-7.76$ & 0.002 \\
Current high blood pressure $^{\beta}$ & 2.59 & $1.25-5.33$ & 0.01 \\
Female sex $^{2}$ & 2.25 & $1.06-4.77$ & 0.034
\end{tabular}

Current high blood pressure ${ }^{\beta}$ : clinic measured systolic blood pressure $\geq 140 \mathrm{mmHg}$ and/or diastolic blood pressure $\geq 90 \mathrm{mmHg}$; AOR: Adjusted odds ratio.

finding is comparable to the upper end of the range $(1.7-28 \%)$ found when ABI was measured by echographic and doppler flow velocity waveform analysis methods [2]. The prevalence of PAD in our study population is also well within the range of several screening studies in the US that used a similar screening technique, and, in African American diabetic patients, found a prevalence of PAD between 14-30\% [29-31]. The low proportion of smokers in our study (5.2\%) reflects the low national smoking prevalence in Uganda [32].

In the multivariable-adjusted analysis, we found that female sex, current high blood pressure, and use of glibenclamide were predictive of PAD. Population based studies have previously reported an association of PAD with female sex [33] and hypertension [34], which we have also shown in our study. In our clinic, the majority of the patients are of the female sex [35]. This pattern may be because females generally outnumber males in the Ugandan population and, in addition, they tend to have better health seeking behaviour [36,37]. We were unable to assess independent association of smoking with PAD because of a very low prevalence of smoking. A low prevalence of smoking has been reported in the general Ugandan population, and the prevalence is even lower in females [32,35,37]. It is therefore possible that the observed lack of association with smoking with PAD may be due to the high female proportion in the setting of a low prevalence of smoking in females. Given this observation, the finding that female sex was an independent predictor of PAD may or may not represent a real association in this population, and, therefore, deserves further investigation in future studies.

Despite international recommendations for use of aspirin, ACEIs, and statins for PAD [18], our study shows that diabetes patients are undertreated with regard to atherosclerotic risk factor modification. This may be because patients with diabetes can be asymptomatic even in the presence of serious cardiovascular complications. PAD screening in these patients may therefore enhance the awareness of active cardiovascular complications and allow for more risk factor treatment. We do appreciate that there can be a high rate of noncompliance to medication for chronic non-communicable disease is in our setting. However, our finding of a high prevalence of 
PAD in the context of under treatment, may suggest the existence of prevention opportunities in this population.

Although sulfonylureas, including glyburide and gliclazide, have been associated with an increased mortality from acute coronary syndrome in type 2 diabetes patients [38], we know of no prior study that has reported an association between glibenclamide use and PAD. This may, therefore, be a spurious finding from our study. However, the association was independent of concurrent metformin use, diabetes duration and severity (as assessed through HbA1c). In addition, those taking insulin were not at increased risk of PAD, indicating the increased risk of PAD in those on glibenclamide may not be related to the known risk of hypoglycemia that occurs with glibenclamide. Thus, our findings may suggest an independent association between PAD and glibenclamide use (Table 3) requiring further investigation.

Previous studies have reported that even among patients with a low $\mathrm{ABI}$ and thus confirmed PAD, absence of "leg" symptoms is not very useful in excluding PAD $[6,20]$. We found that only $20 \%$ of those with PAD had definite claudication, and that over half had no claudication symptoms on the ECQ. This is similar to what has been found by studies in resource rich settings where this tool showed 20\% sensitivity in diagnosing PAD [16]. Our data similarly suggest that claudication symptoms are not very helpful in excluding PAD in Sub-Saharan Africa.

The findings in this report are subject to a number of limitations. First, this was a cross sectional study in a population with diabetes where the risk for PAD is high. Second, the patients studied were from a referral center. These observations imply that our findings may not necessarily represent the general Ugandan population, or those patients presenting in primary care settings. In addition, our findings may not reflect the prevalence of PAD if it was measured using other screening criteria. However, our data suggest that criteria applied in resource-rich settings may as well be applicable in the resource-poor setting.

\section{Conclusion}

In conclusion, PAD was common among diabetes outpatients $\geq 50$ years old presenting at a referral hospital in southwestern Uganda. Given that this is a group at high risk of cardiovascular complications, the high prevalence of PAD in a setting of under-treatment of general cardiovascular risk, call for further study of PAD in this population. For example, future studies could investigate whether screening for PAD in this population using ABIs might lead to increased use of evidence-based treatments that are known to reduce general cardiovascular risk. Future research should also attempt to determine the prevalence and risk factors of PAD in more generalized populations in sub-Saharan Africa.

\section{Abbreviations}

ABI: Ankle-Brachial Index, PAD, Peripheral Artery Disease, AOR, Adjusted Odds Ratio.

\section{Competing interests}

The authors prepared this report in their roles as employees of their respective institutions. They have no financial or other potential conflict of interest with regard to this manuscript.

\section{Author contributions}

SO, AM, RO, SBA, and BHA conceived the study, collected the data, contributed to discussion, and reviewed, edited, and wrote the manuscript. MJS, JR, LAW, CCM, and BHA contributed to discussion and reviewed and edited the manuscript. S.O and C.C.M analyzed the data. SO is the guarantor of this work and, as such, had full access to all the data in the study and takes responsibility for the integrity of the data and the accuracy of the data analysis. All authors read and approved the final manuscript.

\section{Acknowledgements}

We acknowledge that our study was supported in part by funds from the Ruth and Frank Dunlap Research Endowment at Division of Cardiovascular Medicine and the Center for Global Health at the University of Virginia. All authors read and approved the final manuscript.

\section{Author details}

${ }^{1}$ Department of Medicine, Mbarara University of Science and Technology, P.O Box 1410, Mbarara, Uganda. ${ }^{2}$ Department of Medicine, University of Virginia, Charlottesville, Virginia, USA. ${ }^{3}$ Department of Medicine, Mbarara Regional Referral Hospital, Mbarara, Uganda. ${ }^{4}$ Harvard Medical School, Boston, Massachusetts, United States of America. ${ }^{5}$ The Robert M. Berne Cardiovascular Research Center, University of Virginia, Charlottesville, Virginia, USA.

Received: 5 March 2014 Accepted: 5 June 2014

Published: 10 June 2014

\section{References}

1. Mathers CD, Loncar D: Projections of global mortality and burden of disease from 2002 to 2030. PLoS Med 2006, 3(11):e442.

2. Kengne AP, Amoah AGB, Mbanya JC: Cardiovascular complications of diabetes mellitus in sub-Saharan Africa. Circulation 2005, 112(23):3592-3601.

3. Norgren L, Hiatt W, Dormandy J, Nehler M, Harris K, Fowkes F: Inter-society consensus for the management of peripheral arterial disease (TASC II). J Vasc Surg 2007, 45(1):5.

4. Zheng Z-J, Sharrett AR, Chambless LE, Rosamond WD, Nieto FJ, Sheps DS, Dobs A, Evans GW, Heiss G: Associations of ankle-brachial index with clinical coronary heart disease, stroke and preclinical carotid and popliteal atherosclerosis: the Atherosclerosis Risk in Communities (ARIC) Study. Atherosclerosis 1997, 131(1):115-126.

5. Resnick HE, Lindsay RS, McDermott MM, Devereux RB, Jones KL, Fabsitz RR, Howard BV: Relationship of high and low ankle brachial index to all-cause and cardiovascular disease mortality. Circulation 2004, 109(6):733-739.

6. Hirsch AT, Criqui MH, Treat-Jacobson D, Regensteiner JG, Creager MA, Olin JW, Krook SH, Hunninghake DB, Comerota AJ, Walsh ME: Peripheral arterial disease detection, awareness, and treatment in primary care. Jama 2001, 286(11):1317-1324.

7. Elhadd T, Robb R, Jung R, Stonebridge P, Belch J: Pilot study of prevalence of asymptomatic peripheral arterial occlusive disease in patients with diabetes attending a hospital clinic. Pract Diab Int 1999, 16(6):163-166.

8. Fowkes F, Murray G, Butcher I, Folsom A, Hirsch A, Couper D, DeBacker G, Kornitzer M, Newman A, Sutton-Tyrrell K: Development and validation of an ankle brachial index risk model for the prediction of cardiovascular events. Eur J Prev Cardiol 2014, 21(3):310-320.

9. Criqui MH, Langer RD, Fronek A, Feigelson HS, Klauber MR, McCann TJ, Browner D: Mortality over a period of 10 years in patients with peripheral arterial disease. N Engl J Med 1992, 326(6):381-386.

10. Murabito JM, Evans JC, Larson MG, Nieto K, Levy D, Wilson PW: The ankle-brachial index in the elderly and risk of stroke, coronary disease, and death: the Framingham Study. Arch Intern Med 2003, 163(16):1939. 
11. van der Meer IM, Bots ML, Hofman A, del Sol Al, van der Kuip DA, Witteman JC: Predictive value of noninvasive measures of atherosclerosis for incident myocardial infarction. Circulation 2004, 109(9):1089-1094.

12. Collaboration ABI, Fowkes F, Murray G, Butcher I, Heald C, Lee R, Chambless L, Folsom A, Hirsch A, Dramaix M: Ankle brachial index combined with Framingham risk score to predict cardiovascular events and mortality. JAMA 2008, 300(2):197-208.

13. Criqui $M H$, Vargas V, Denenberg JO, Ho E, Allison M, Langer RD, Gamst A, Bundens WP, Fronek A: Ethnicity and Peripheral Arterial Disease The San Diego Population Study. Circulation 2005, 112(17):2703-2707.

14. Allison MA, Criqui MH, McClelland RL, Scott JAM, McDermott MM, Liu K, Folsom AR, Bertoni AG, Sharrett AR, Homma S: The effect of novel cardiovascular risk factors on the ethnic-specific odds for peripheral arterial disease in the Multi-Ethnic Study of Atherosclerosis (MESA). J Am Coll Cardiol 2006, 48(6):1190-1197.

15. Association AD: Peripheral arterial disease in people with diabetes. Clinical Diabetes 2004, 22(4):181-189.

16. PERIPHERAL IO: Peripheral arterial disease in people with diabetes. Diabetes Care 2003, 26(12):3333.

17. Meijer WT, Hoes AW, Rutgers D, Bots ML, Hofman A, Grobbee DE: Peripheral arterial disease in the elderly: the Rotterdam Study. Arterioscler Thromb Vasc Biol 1998, 18(2):185-192.

18. Rooke TW, Hirsch AT, Misra S, Sidawy AN, Beckman JA, Findeiss LK, Golzarian J, Gornik HL, Halperin JL, Jaff MR: 2011 ACCF/AHA focused update of the guideline for the management of patients with peripheral artery disease (updating the 2005 guideline) a report of the American college of cardiology foundation/American heart association task force on practice guidelines. J Am Coll Cardiol 2011, 58(19):2020-2045.

19. Blodget E, Shen C, Aldrovandi G, Rollie A, Gupta SK, Stein JH, Dubé MP: Relationship between Microbial Translocation and Endothelial Function in HIV Infected Patients. PLoS One 2012, 7(8):e42624

20. Creager MA, Belkin M, Bluth El, Casey DE, Chaturvedi S, Dake MD, Fleg UL, Hirsch AT, Jaff MR, Kern JA: 2012 ACCF/AHA/ACR/SCAI/SIR/STS/SVM/SVN/ SVS Key Data Elements and Definitions for Peripheral Atherosclerotic Vascular Disease: A Report of the American College of Cardiology Foundation/American Heart Association Task Force on Clinical Data Standards (Writing Committee to Develop Clinical Data Standards for Peripheral Atherosclerotic Vascular Disease). J Am Coll Cardiol 2012, 59(3):294-357.

21. Lend G, Fowkes F: The Edinburgh Claudication Questionnaire: an improved version of the WHO/Rose Questionnaire for use in epidemiological surveys. J Clin Epidemiol 1992, 45(10):1101-1109.

22. Holland-Letz T, Endres HG, Biedermann S, Mahn M, Kunert J, Groh S, Pittrow D, Von Bilderling P, Sternitzky R, Diehm C: Reproducibility and reliability of the ankle-brachial index as assessed by vascular experts, family physicians and nurses. Vasc Med 2007, 12(2):105-112.

23. Heald C, Fowkes F, Murray G, Price J: Risk of mortality and cardiovascular disease associated with the ankle-brachial index: Systematic review. Atherosclerosis 2006, 189(1):61-69.

24. Marso SP, Hiatt WR: Peripheral arterial disease in patients with diabetes. J Am Coll Cardiol 2006, 47(5):921-929.

25. Ashwell M, Gunn P, Gibson S: Waist-to-height ratio is a better screening tool than waist circumference and BMI for adult cardiometabolic risk factors: systematic review and meta-analysis. Obes Rev 2012, 13(3):275-286.

26. Lorenzo C, Williams K, Hunt KJ, Haffner SM: The National Cholesterol Education Program-Adult Treatment Panel III, International Diabetes Federation, and World Health Organization definitions of the metabolic syndrome as predictors of incident cardiovascular disease and diabetes. Diabetes Care 2007, 30(1):8-13.

27. Rolfe M: Macrovascular disease in diabetics in Central Africa. $\mathrm{Br}$ Med J (Clin Res Ed) 1988, 296(6635):1522.

28. Elmahdi E, Kaballo A, Mukhtar E: Features of non-insulin-dependent diabetes mellitus (NIDDM) in the Sudan. Diabetes Res Clin Pract 1991, 11(1):59-63.

29. Aponte J: The prevalence of peripheral arterial disease (PAD) and PAD risk factors among different ethnic groups in the US Population. J Vasc Nurs 2012, 30(2):37-43.

30. Lange S, Diehm C, Darius H, Haberl R, Allenberg JR, Pittrow D, Schuster A, von Stritzky B, Tepohl G, Trampisch HJ: High prevalence of peripheral arterial disease but low antiplatelet treatment rates in elderly primary care patients with diabetes. Diabetes Care 2003, 26(12):3357-3358.
31. Gregg EW, Sorlie P, Paulose-Ram R, Gu Q, Eberhardt MS, Wolz M, Burt V, Curtin L, Engelgau M, Geiss L: Prevalence of Lower-Extremity Disease in the US Adult Population $\geq 40$ Years of Age With and Without Diabetes 1999-2000 National Health and Nutrition Examination Survey. Diabetes Care 2004, 27(7):1591-1597.

32. Maher D, Waswa L, Baisley K, Karabarinde A, Unwin N, Grosskurth H: Distribution of hyperglycaemia and related cardiovascular disease risk factors in low-income countries: a cross-sectional population-based survey in rural Uganda. Int J Epidemio/ 2011, 40(1):160-171.

33. Aboyans V, Criqui MH, McClelland RL, Allison MA, McGrae McDermott M Goff DC, Manolio TA: Intrinsic contribution of gender and ethnicity to normal ankle-brachial index values: the Multi-Ethnic Study of Atherosclerosis (MESA). J Vasc Surg 2007, 45(2):319-327.

34. Guerchet M, Aboyans V, M'Belesso P, Mouanga AM, Salazar J, Bandzouzi B, Tabo A, Lacroix P, Preux P-M: 241 Particularities of the epidemiology of lower-extremities peripheral artery disease in Central Africa. Arch Cardiovasc Dis Supplements 2010, 2(1):77.

35. Namusisi O, Sekandi JN, Kasasa S, Wasswa P, Kamara NT, Medard B, Mihayo P, Gitta SN, Mukanga D: Risk factors for non-communicable diseases in rural Uganda: a pilot surveillance project among diabetes patients at a referral hospital clinic. Pan African Medical Journal 2011, 10(1):47.

36. Lawson D: Determinants of Health Seeking Behaviour in Uganda: Is it Just Income and User Fees that are Important? Manchester, England: University of Manchester; 2004.

37. Inc UBoSUall: Uganda Demographic and Health Survey. In ICF International Inc. Calverton, Maryland: UBOS; 2012.

38. Monami M, Luzzi C, Lamanna C, Chiasserini V, Addante F, Desideri CM, Masotti G, Marchionni N, Mannucci E: Three year mortality in diabetic patients treated with different combinations of insulin secretagogues and metformin. Diabetes Metab Res Rev 2006, 22(6):477-482.

doi:10.1186/1471-2261-14-75

Cite this article as: Okello et al:: Prevalence of lower extremity

Peripheral artery disease among adult diabetes patients in

Southwestern Uganda. BMC Cardiovascular Disorders 2014 14:75.

\section{Submit your next manuscript to BioMed Central and take full advantage of:}

- Convenient online submission

- Thorough peer review

- No space constraints or color figure charges

- Immediate publication on acceptance

- Inclusion in PubMed, CAS, Scopus and Google Scholar

- Research which is freely available for redistribution

Submit your manuscript at www.biomedcentral.com/submit
C) Biomed Central 